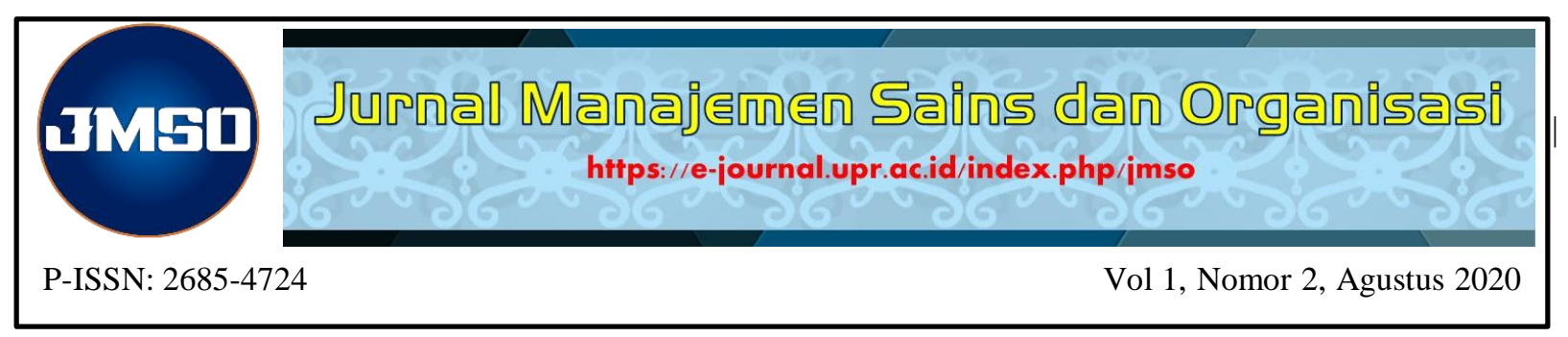

\title{
Pengaruh Word Of Mouth Communication Dan Kualitas Makanan Terhadap Kepuasan Konsumen Dengan Keputusan Pembelian Sebagai Variabel Intervening \\ (Studi Pada Restaurant J'S Kitchen And Lounge Kalawa Waterpark, Palangka Raya)
}

\author{
Sukini $^{1}$ \\ Fakultas Ekonomi dan Bisnis \\ Universitas Palangka Raya, Indonesia \\ Bambang Mantikei ${ }^{2)}$ \\ Program Magister Manajemen Pascasarjana \\ Universitas Palangka Raya, Indonesia \\ Yoga Manurung ${ }^{3}$ \\ Fakultas Ekonomi dan Bisnis \\ Universitas Palangka Raya, Indonesia \\ Email: sukini918@gmail.com
}

\begin{abstract}
Abstrak
Tujuan - Penelitian ini bertujuan untuk memberikan penjelasan secara empiris tentang pengaruh word of mouth communication dan kualitas makanan terhadap kepuasan konsumen dengan keputusan pembelian sebagai variabel intervening.

Desain/Metodelogi/Pendekatan - Metode penelitian yang digunakan kuantitatif. Sampel dalam penelitian ini terdiri dari 119 pengunjung restoran. Penentuan sampel menggunakan teknik purposive sampling. Proses analisis data menggunakan bantuan SmartPLS.

Temuan - Hasil penelitian menunjukkan keputusan pembelian memediasi pengaruh Word Of Mouth Communication terhadap kepuasan konsumen. Temuan lainnya dijelaskan pada pembahasan.
\end{abstract}

Kata kunci: Word Of Mouth Communication, Kualitas Makanan, Kepuasan Konsumen, Keputusan Pembelian.

\section{The Effect Of Word Of Mouth Communication and Food Quality Towards Consumer Satisfaction With Purchase Decisions as an Intervening Variable (Study at Restaurant J'S Kitchen And Lounge Kalawa Waterpark, Palangka Raya)}

\begin{abstract}
Purpose - This study aims to provide an empirical explanation of the effect of word of mouth communication and food quality on consumer satisfaction with purchasing decisions as an intervening variable.

Design / Methodology / Approach - The research method used is quantitative. The sample in this study consisted of 119 restaurant visitors. Determination of the sample using purposive sampling technique. The data analysis process uses the help of SmartPLS.

Findings - The results show that purchasing decisions mediate the influence of Word of Mouth Communication on customer satisfaction. Other findings are described in the discussion
\end{abstract}

Keywords: Word Of Mouth Communication, Food Quality, Consumer Satisfaction, Purchasing Decisions.

Jurnal Manajemen Sains dan Organisasi Vol 1, No 2, 2020 pp. $83-97$ FEB UPR Publishing $2685-4724$
Sukini, Bambang Mantikei, and Yoga Manurung. Published in the Jurnal Manajemen sains dan Organsasi. Published by FEB UPR Publishing Limited. This article is published under the Creative Commons Attribution (CC BY 4.0) licence. Anyone may reproduce, distribute, translate and create derivative works of this article (for both commercial and non-commercial purposes), subject to full attribution to the original publication and authors. 


\section{PENDAHULUAN}

Komunikasi pemasaran merupakan suatu alat yang digunakan sebagai sarana untuk menginformasikan, membujuk dan mengingatkan konsumen tentang produk yang mereka jual dan ditujukan untuk performance pemasaran. Hal ini sejalan dengan komunikasi pemasaran menurut Kotler dan Keller (2008), Komunikasi pemasaran adalah sarana dimana perusahaan berusaha menginformasikan, membujuk dan mengingatkan konsumen secara langsung maupun tidak langsung tentang produk dan merek yang mereka jual. Dilihat dari sisi konsumen, komunikasi sangat membantu konsumen dalam membuat keputusan pembelian, karena informasi sangat membantu konsumen untuk membeli (Irwan, 2008). Konsumen sebelum melakukan pembelian cenderung melalui proses pencarian informasi produk atau jasa yang mereka inginkan. Proses pencarian informasi ini sering didapatkan dari orang terdekat seperti keluarga, saudara, dan teman. Pencarian informasi ini menghasilkan suatu bentuk komunikasi. Komunikasi ini dalam realisasinya dikenal dengan word of mouth communication atau komunikasi dari mulut ke mulut. Pencarian informasi membuat calon konsumen melakukan komunikasi dengan konsumen yang puas dengan pelayanan restoran dan kualitas makanan sehingga konsumen melakukan word of mouth communication dengan sukarela. Menurut Setiawan (2013), kualitas makanan merupakan peranan penting dalam pemutusan pembelian konsumen, sehingga dapat diketahui bila kualitas makanan meningkat, maka keputusan pembelian akan meningkat juga. Word of mouth communication secara sukarela ini sering disebut sebagai rekomendasi. Rekomendasi dari konsumen tersebut memudahkan calon konsumen untuk membuat keputusan pembelian dan jika sudah melakukan pembelian konsumen akan merasa puas karena rekomendasi tersebut memang sesuai dengan rekomendasi yang diberikan. Berikut ini adalah data penjualan dan data jumlah pengunjung Restaurant J'S Kitchen and Lounge pada tahun 2018:

Tabel 1: Data Penjualan dan Jumlah Pengunjung Restaurant J'S Kitchen and Lounge Tahun 2018

\begin{tabular}{lcc}
\hline \multicolumn{1}{c}{ Bulan } & Penjualan & Pengunjung (orang) \\
\hline Januari & Rp.53.710.500 & 448 \\
Februari & Rp.46.927.000 & 391 \\
Maret & Rp.45.929.000 & 383 \\
April & Rp.79.057.500 & 659 \\
Mei & Rp.68.007.200 & 567 \\
Juni & Rp.68.074.000 & 567 \\
Juli & Rp.41.809.400 & 348 \\
Agustus & Rp.38.106.350 & 318 \\
September & Rp.41.619.000 & 347 \\
Oktober & Rp.47.057.000 & 392 \\
November & Rp.67.215.000 & 560 \\
Desember & Rp.57.861.000 & 482 \\
\hline Total & Rp.655.373.050 & 5.461 \\
\hline Rata-rata & Rp.54.614.420 & 455
\end{tabular}

Sumber: Laporan Data Penjualan dan Jumlah Pengunjung Restaurant J'S Kitchen and Lounge Tahun 2018 


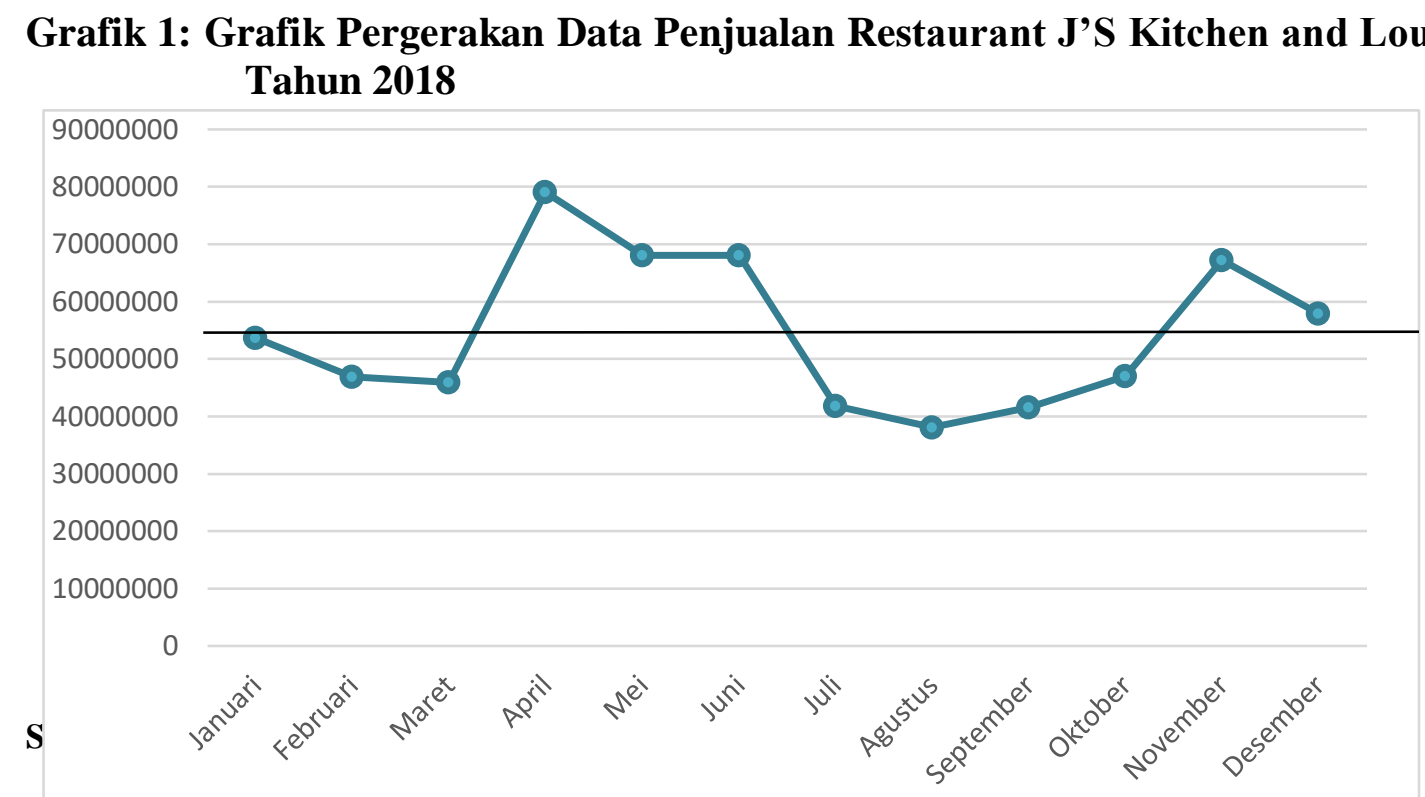

Grafik 2: Grafïk Pergerakan Jumlah Pengunjung Restaurant J'S Kitchen and Lounge Tahun 2018

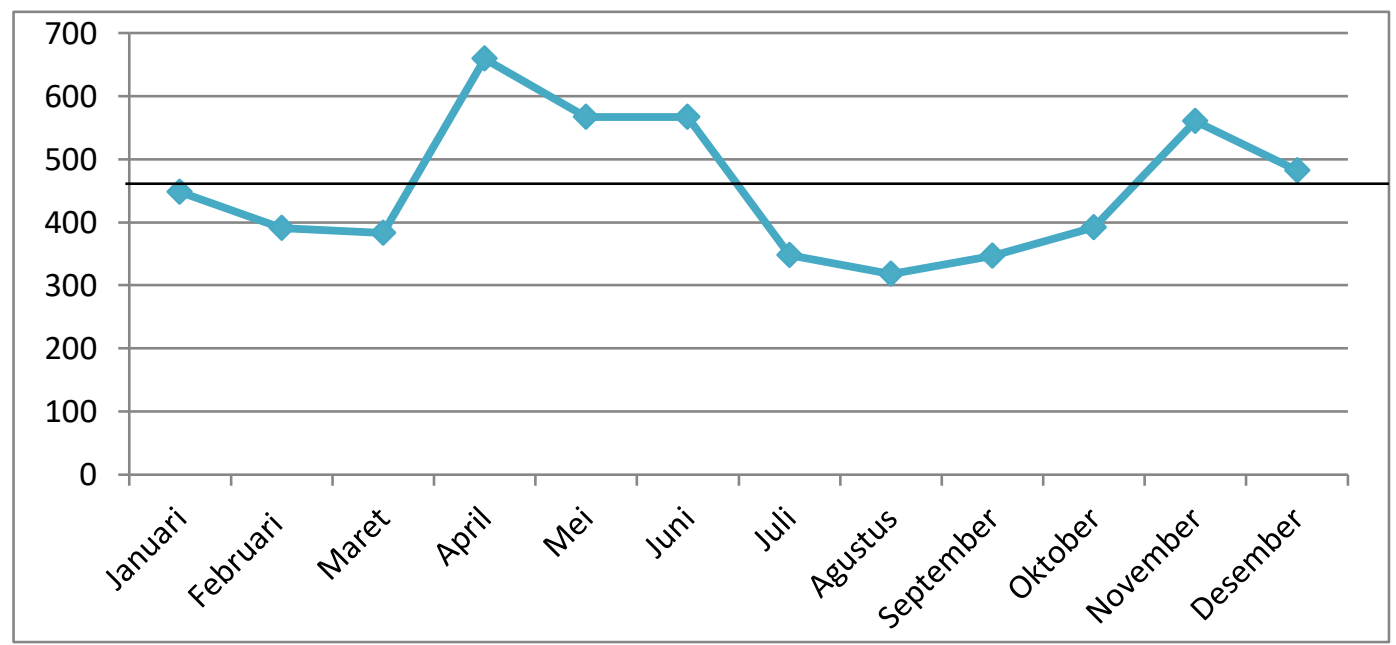

Sumber: Data jumlah pengunjung diolah, 2019

Berdasarkan data penjualan dan jumlah pengunjung di atas, dapat dilihat bahwa ada ketidakstabilan pada setiap bulannya. Hal tersebut menjadi perhatian yang sangat penting bagi pemilik restoran, untuk menjadikan restoran unggul dibandingkan dengan restoran lainnya. Ketidakstabilan penjualan dan jumlah pengunjung dapat diminimalkan dengan meningkatkan kualitas makanan agar sesuai dengan yang diharapkan konsumen. Dengan meningkatkan kualitas makanan yang disajikan maka konsumen akan merekomendasikan restoran kepada calon konsumen baru, sehingga dapat meningkatkan penjualan dan jumlah pengunjung.

Menurut Fahima (2007) bahwa hal yang paling mendasar dalam terciptanya word 
of mouth adalah ketika konsumen merasakan kepuasan akan produk yang telah dikonsumsinya. Pembelian yang didasarkan pada rekomendasi positif dari teman, keluarga, atau sahabat akan berdampak pada kepuasan yang mereka dapatkan, karena harapan dan keinginan yang telah dipenuhi dari informasi yang diperoleh lebih bersifat positif dan dipercaya. (Nugraha dkk, 2015) dalam penelitiannya menunjukkan bahwa word of mouth memiliki pengaruh yang signifikan terhadap kepuasan konsumen dengan nilai koefisien jalur sebesar 0,351 atau $35,1 \%$ dan koefisien determinasi sebesar 70,481 atau $48,1 \%$.

H1: Word of mouth communication berpengaruh positif dan signifikan terhadap kepuasan konsumen.

Semakin tinggi kualitas dari sebuah produk atau makanan maka akan semakin tinggi juga pengaruhnya terhadap pelanggan sehingga akan menimbulkan kepuasan. Kualitas makanan memiliki pengaruh secara langsung terhadap kepuasan pelanggan. Handojo dan Adinugraha (2015) kualitas makanan adalah atribut yang paling penting dari keseluruhan kualitas layanan dan memiliki hubungan positif dengan kepuasan dan loyalitas pelanggan. (Handojo dan Adinugraha, 2015) dalam penelitiannya menunjukkan bahwa kualitas makanan secara parsial berpengaruh terhadap kepuasan konsumen, dengan nilai tsig sebesar 0.029 atau $<0,05$, maka Ho ditolak pada tingkat signifikansi 5\%. (Sugianto dan Sugiharto, 2013) dalam penelitiannya menunjukkan bahwa food quality berpengaruh terhadap kapuasan pelanggan dengan nilai $p$ values sebesar 0.028 atau $<0,05$, maka Ho ditolak pada tingkat signifikansi 5\%.

$\mathrm{H} 2$ : Kualitas makanan berpengaruh positif dan signifikan terhadap kepuasan konsumen

Nugraha dkk (2015) informasi positif yang didapat oleh calon konsumen mengenai Kober Mie Setan mendorong untuk melakukan keputusan pembelian pada Kober Mie Setan. Konsumen akan melakukan kegiatan word of mouth dan menceritakan pengalaman mereka setelah mengkonsumsi produk kepada orang lain seperti sahabat, kerabat, dan teman. Apabila pengalaman yang diperoleh positif maka word of mouth yang dilakukan juga positif dan apabila pengalaman yang didapat tidak sesuai dengan rekomendasi maka word of mouth tidak berjalan dengan baik. (Nugraha dkk, 2015) dalam penelitiannya menunjukkan bahwa variabel word of mouth memiliki pengaruh signifikan terhadap variabel keputusan pembelian yang ditunjukkan oleh nilai $p$ values sebesar $0,000(\mathrm{p}<0,05)$. (Nugraha dan Saraswati, 2015) dalam penelitiannya menunjukkan bahwa t hitung 52,319 lebih besar dari t tabel 2,31 yang berarti word of mouth berpengaruh secara simultan terhadap keputusan pembelian.

H3: Word of mouth communication berpengaruh positif dan signifikan terhadap keputusan pembelian

Menurut Setiawan (2013), kualitas makanan merupakan peranan penting dalam keputusan pembelian konsumen, sehingga dapat diketahui bila kualitas makanan meningkat, maka keputusan pembelian akan meningkat juga, melalui indikator variabel food quality dapat meningkatkan keputusan pembelian roti kecik di toko roti Ganep's dengan indikator warna, penampilan, bentuk, tekstur, aroma dan rasa. (Sari, 2017) dalam penelitiannya menunjukkan bahwa variabel kualitas makanan terhadap keputusan pembelian diperoleh nilai t hitung 7,878 lebih besar dari t tabel 1,980 dengan $p$ values 
$(0,000)<0,05$ berarti kualitas makanan berpengaruh signifikan terhadap keputusan pembelian konsumen di Vien's Selat Segar dan Sup Matahari Solo.

88

H4: Kualitas makanan bepengaruh positif dan signifikan terhadap keputusan keputusan pembelian

Nugraha dkk (2015) konsumen cenderung mempertimbangkan beberapa faktor sebelum memutuskan untuk membeli, karena keputusan yang tepat akan berdampak pada tingkat kepuasan yang tinggi yang sesuai dengan harapan dan keinginan bagi konsumen. Dengan itu, harapan dan keinginan konsumen yang telah terpenuhi akan meningkatkan kepuasan bagi konsumen. Keputusan pembelian mempunyai pengaruh terhadap kepuasan konsumen. Seperti yang telah dijelaskan bahwa sebelum konsumen memutuskan untuk membeli, tahapan yang harus dilewati yaitu struktur keputusan pembelian. Konsumen akan dikatakan puas atas pembelian produk atau jasa yang telah dibelinya karena harapan dan keinginannya sebagai konsumen telah terpenuhi. (Nugraha dkk, 2015) dalam penelitiannya menunjukkan bahwa variabel keputusan pembelian berpengaruh signifikan terhadap kepuasan konsumen yang ditunjukkan oleh nilai $p$ values $0,000(\mathrm{p}<0,05)$.

H5: Keputusan pembelian berpengaruh positif dan signifikan terhadap kepuasan konsumen.

Rahmadevita (2011) dengan adanya word of mouth communication, maka rangsangan untuk membeli semakin kuat. Hal tersebut dikarenakan konsumen yang memberikan informasi tentang produk yang telah dikonsumsinya kepada calon konsumen baru lebih dipercaya, dan berdampak pada keputusan pembelian oleh calon konsumen baru. Rekomendasi dari teman yang terpercaya tersebut membuat calon konsumen melakukan keputusan pembelian, setelah melakukan pembelian dan mengkonsumsi produk yang direkomendasikan akan terjadi kepuasan karena harapan dan keinginan yang telah terpenuhi sesuai dengan rekomendasi yang diberikan. (Nugraha dkk, 2015) dalam penelitiannya menunjukkan bahwa word of mouth berpengaruh signifikan terhadap kepuasan konsumen melalui keputusan pembelian sebesar 68,5\%.

H6: Word of mouth communication berpengaruh positif dan signifikan terhadap kepuasan konsumen melalui keputusan pembelian

Menurut Sugianto dan Sugiharto (2013), dengan adanya food quality maka keputusan pembelian konsumen terhadap produk tersebut akan meningkat. Setelah melakukan pembelian dan mengkonsumsi produk yang berkualitas maka konsumen akan merasa puas karena produk sesuai kualitas yang ditawarkan oleh restoran Yung Ho Surabaya. (Setiawan, 2013) dalam penelitiannya menunjukkan bahwa nilai signifikansi food quality di bawah 0,05, maka food quality secara parsial food quality mempengaruhi keputusan pembelian. (Sugianto dan Sugiharto, 2013) dalam penelitiannya menunjukkan bahwa nilai signifikansi t hitung 0.028 lebih kecil dari $0.05(\alpha=5 \%)$ yang berarti food quality memiliki pengaruh yang signifikan terhadap kepuasan konsumen di restoran Yung Ho Surabaya.

H7: Kualitas makanan berpengaruh positif dan signifikan terhadap kepuasan konsumen melalui keputusan pembelian 


\section{Gambar 1: Kerangka Pemikiran}

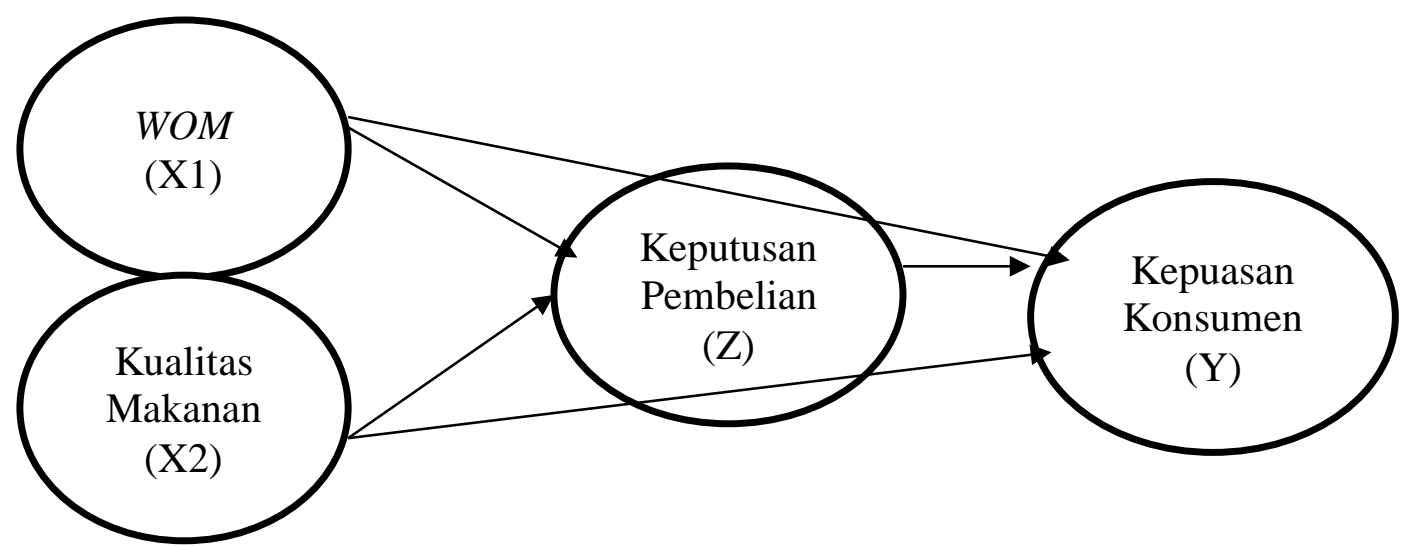

Sumber: Konsep yang dikembangkan peneliti

Desain penelitian yang digunakan dalam penelitian ini adalah Explanatory Research (penelitian penjelasan) dengan pendekatan kuantitatif. Sumber data diperoleh dari penyebaran kusioner. Sampel dalam penelitian ini berjumlah 119 pengunjung yang datang di restoran yang dipilih dengan purposive sampling.

Variabel dan indikator yang digunakan dalam penelitian ini dapat dilihat dalam tabel berikut ini:

\section{Tabel 2: Identifikasi Variabel}

\begin{tabular}{|c|c|c|}
\hline Variabel & Definisi & Indikator Variabel \\
\hline $\begin{array}{l}\text { Word of } \quad \text { mouth } \\
\text { communication }(\mathrm{X} 1)\end{array}$ & $\begin{array}{l}\text { Komunikasi yang dilakukan oleh konsumen yang } \\
\text { telah melakukan pembelian dan menceritakan } \\
\text { pengalamannya tentang produk dan jasa tersebut } \\
\text { kepada orang lain. }\end{array}$ & $\begin{array}{l}\text { 1. Membicarakan } \\
\text { 2. Merekomendasikan } \\
\text { 3. Mendorong }\end{array}$ \\
\hline $\begin{array}{l}\text { Kualitas makanan (X2) } \\
\text { Essinger dan Wylie (2003) }\end{array}$ & $\begin{array}{l}\text { Kualitas produk adalah karakteristik dari produk atau } \\
\text { jasa yang pada kemampuannya menanggung janji } \\
\text { atau sisipan untuk memuaskan kebutuhan pelanggan. }\end{array}$ & $\begin{array}{ll}\text { 1. } & \text { Kualitas dalam hal rasa } \\
\text { 2. } & \text { Kuantitas atau porsi } \\
\text { 3. } & \text { Variasi menu } \\
\text { 4. } & \text { Cita rasa yang khas } \\
\text { 5. } & \text { Higienitas } \\
\text { 6. } & \text { Inovasi }\end{array}$ \\
\hline $\begin{array}{l}\text { Keputusan pembelian (Z) } \\
\text { Kotler dan Keller (2012) }\end{array}$ & $\begin{array}{l}\text { Suatu proses dimana konsumen melewati lima tahap, } \\
\text { yaitu pengenalan masalah, pencarian informasi, } \\
\text { evaluasi alternatif, keputusan pembelian, dan perilaku } \\
\text { pasca pembelian, yang dimulai jauh sebelum } \\
\text { pembelian aktual dilakukan dan memiliki dampak } \\
\text { yang lama setelah itu. }\end{array}$ & $\begin{array}{ll}\text { 1. } & \text { Merek } \\
\text { 2. } & \text { Diler } \\
\text { 3. } & \text { Kualitas } \\
\text { 4. } & \text { Waktu } \\
\text { 5. } & \text { Metode pembayaran }\end{array}$ \\
\hline $\begin{array}{l}\text { Kepuasan konsumen (Y) } \\
\text { Zeithaml (2006) }\end{array}$ & $\begin{array}{l}\text { Respon atau tanggapan konsumen mengenai } \\
\text { pemenuhan kebutuhan. Kepuasan merupakan } \\
\text { penilaian mengenai ciri atau keistimewaan produk } \\
\text { atau jasa, atau produk itu sendiri, yang menyediakan } \\
\text { tingkat kesenangan konsumen berkaitan dengan } \\
\text { pemenuhan kebutuhan konsumsi konsumen. }\end{array}$ & $\begin{array}{ll}\text { 1. } & \text { Fulfillment } \\
\text { 2. } & \text { Pleasure } \\
\text { 3. } & \text { Ambivalence }\end{array}$ \\
\hline
\end{tabular}

Sumber: Konsep yang dikembangkan dalam penelitian ini, 2019

Data dianalisis dengan menggunakan metode Partial Least Square (PLS) dan menggunakan tools SmartPLS. PLS adalah salah satu metode alternatif SEM (structural equation modeling) yang digunakan untuk mengatasi permasalahan hubungan antar variabel, jumlah sampel tidak harus banyak dan tidak memerlukan banyak asumsi. 


\section{HASIL DAN PEMBAHASAN}

Setelah pengumpulan data dengan mengunakan kuesioner yang disebarkan kepada responden yakni seluruh pengunjung yang datang ke restoran yang berjumlah 119 orang. Informasi tentang karakteristik responden dapat dilihat pada Tabel 3. berikut ini:

Tabel 3: Karakteristik Responden

\begin{tabular}{lcc}
\hline \multicolumn{1}{c}{ Karakteristik } & Frekuensi & \% \\
Laki-Laki & 70 & $59 \%$ \\
Perempuan & 49 & $41 \%$ \\
Total & $\mathbf{1 1 9}$ & $\mathbf{1 0 0 \%}$ \\
$18-25$ tahun & 23 & $19 \%$ \\
$26-33$ tahun & 36 & $30 \%$ \\
$34-41$ tahun & 34 & $29 \%$ \\
$>$ 41 tahun & 26 & $22 \%$ \\
Total & $\mathbf{1 1 9}$ & $\mathbf{1 0 0 \%}$ \\
\hline Pelajar/Mahasiswa & 12 & $10 \%$ \\
PNS & 21 & $20 \%$ \\
Wiraswasta & 52 & $44 \%$ \\
IRT & 10 & $8 \%$ \\
Lainnya & 21 & $18 \%$ \\
Total & $\mathbf{1 1 9}$ & $\mathbf{1 0 0 \%}$ \\
$<$ Rp. 2.500.000 & 18 & $16 \%$ \\
Rp. 2.600.000 - Rp. 5.000.000 & 23 & $19 \%$ \\
Rp. 5.100.000 - Rp. 7.500 .000 & 23 & $19 \%$ \\
Rp. 7.600.000 - Rp. 10.000 .000 & 23 & $19 \%$ \\
$>$ Rp. 10.000.000 & 32 & $27 \%$ \\
Total & $\mathbf{1 1 9}$ & $\mathbf{1 0 0 \%}$ \\
& &
\end{tabular}

\section{Sumber: Data primer diolah, 2019}

Tabel di atas menunjukkan bahwa responden yang berjenis laki-laki berjumlah 70 orang atau 59\% dari total keseluruhan sampel. Sedangkan responden yang berjenis kelamin perempuan berjumlah 49 orang atau $41 \%$ dari total keseluruhan sampel. Responden yang berusia 18-25 tahun sebanyak 23 orang atau $19 \%$ dari total keseluruhan sampel. Responden yang berusia 26-33 tahun sebanyak 36 orang atau 30\% dari total keseluruhan sampel. Responden dengan usia 34-41 sebanyak 34 orang atau $29 \%$ dari total keseluruhan sampel. Responden dengan usia $>41$ tahun sebanyak 26 orang atau $22 \%$ dari total keseluruhan sampel. Responden dengan pekerjaan sebagai pelajar/mahasiswa sebanyak 12 orang atau $10 \%$ dari total keseluruhan sampel. Responden dengan pekerjaan sebagai PNS sebanyak 21 orang atau 20\% dari total keseluruhan sampel. Responden dengan pekerjaan sebagai wiraswasta 52 orang atau $44 \%$ dari total keseluruhan sampel. Responden dengan pekerjaan sebagai ibu rumah tangga sebanyak 10 orang atau $8 \%$ dari total keseluruhan sampel. Responden dengan pekerjaan lainnya sebanyak 21 orang atau $18 \%$ dari total keseluruhan sampel. Responden dengan penghasilan <Rp. 2.500 .000 sebanyak 18 orang atau $16 \%$ dari total keseluruhan sampel. Responden dengan 
penghasilan Rp. 2.600.000 - Rp. 5.000.000 sebanyak 23 orang atau 19\% dari total keseluruhan sampel. Responden dengan penghasilan Rp. 5.100.000 - Rp. 7.500.00 sebanyak 23 orang atau $19 \%$ dari total keseluruhan sampel. Responden dengan penghasilan Rp. 7.600.000 - Rp. 10.000.000 sebanyak 23 orang atau $19 \%$ dari total keseluruhan sampel. Responden dengan penghasilan >Rp. 10.000 .000 sebanyak 32 orang atau $27 \%$ dari total keseluruhan sampel.

\section{Evaluasi Measurement Model (Outer Model)}

Adapun model pengukuran untuk uji validitas dan reliabilitas, koefisien determinasi model dan koefisien jalur, dapat dilihat pada Gambar 2 berikut:

\section{Gambar 2: Tampilan Hasil PLS Algorithm}

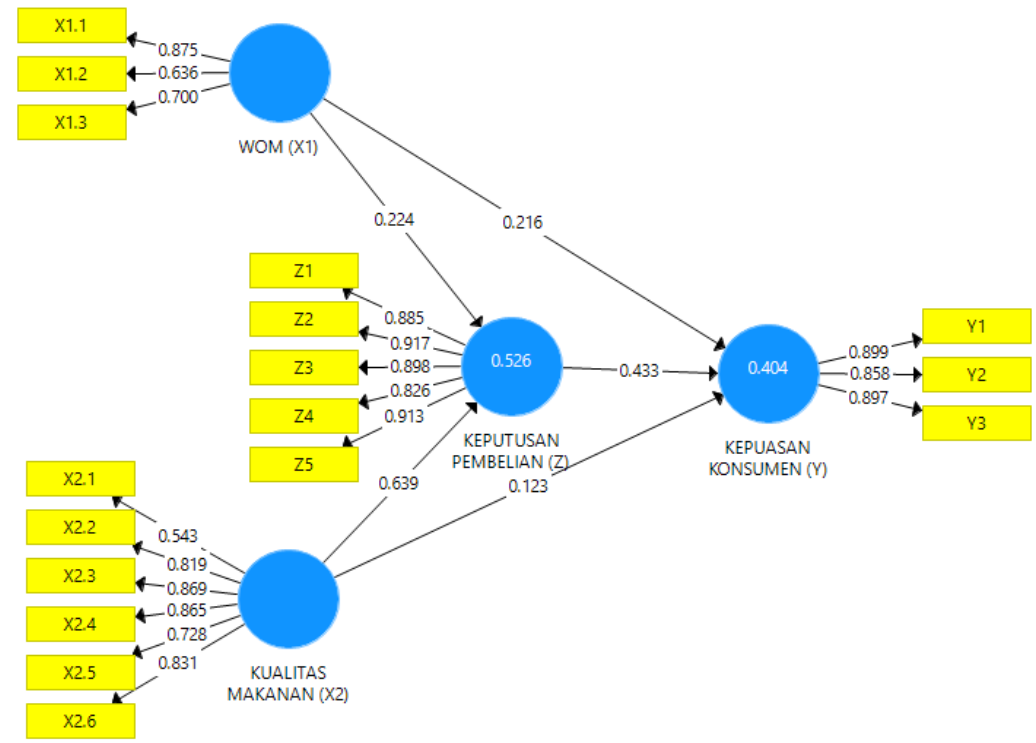

Sumber: Hasil Perhitungan Akhir Algorithm PLS

Sedangkan untuk rangkuman hasil uji validitas dan hasil uji reliabilitas dapat dilihat pada Tabel 4 dan Tabel 5 sebagai berikut:

Tabel 4: Hasil Uji Validitas

\begin{tabular}{|c|c|c|c|c|}
\hline $\begin{array}{c}\text { Measurement } \\
\text { Model }\end{array}$ & Hasil & & $\begin{array}{c}\text { Nilai } \\
\text { Kritis } \\
\end{array}$ & $\begin{array}{c}\text { Evaluasi } \\
\text { Model }\end{array}$ \\
\hline \multicolumn{5}{|c|}{ Outer Model } \\
\hline \multirow{5}{*}{$\begin{array}{l}\text { Discriminant } \\
\text { Validity }\end{array}$} & Variabel & $A V E$ & \multirow{5}{*}{$>0,5$} & \\
\hline & WOM & 0,554 & & Valid \\
\hline & Kualitas Makanan & 0,615 & & Valid \\
\hline & Keputusan Pembelian & 0,789 & & Valid \\
\hline & Kepuasan Konsumen & 0,782 & & Valid \\
\hline $\begin{array}{l}\text { Convergen } \\
\text { Validity }\end{array}$ & Indikator & $\begin{array}{c}\text { Cross } \\
\text { Loading }\end{array}$ & & \\
\hline & X1.1 Membicarakan & 0,875 & & Valid \\
\hline
\end{tabular}




\begin{tabular}{|c|c|c|c|c|c|}
\hline $\begin{array}{c}\text { Measurement } \\
\text { Model }\end{array}$ & & Hasil & & $\begin{array}{c}\text { Nilai } \\
\text { Kritis }\end{array}$ & $\begin{array}{c}\text { Evaluasi } \\
\text { Model }\end{array}$ \\
\hline & $\mathrm{X} 1.2$ & Merekomendasikan & 0,636 & \multirow{16}{*}{$>0,5$} & Valid \\
\hline & $\mathrm{X} 1.3$ & Mendorong & 0,700 & & Valid $_{03}$ \\
\hline & $\mathrm{X} 2.1$ & Kualitas dalam hal rasa & 0,543 & & Valid \\
\hline & $\mathrm{X} 2.2$ & Kuantitas atau porsi & 0,819 & & Valid \\
\hline & $\mathrm{X} 2.3$ & Variasi menu & 0,869 & & Valid \\
\hline & $\mathrm{X} 2.4$ & Cita rasa yang khas & 0,865 & & Valid \\
\hline & $\mathrm{X} 2.5$ & Higienitas & 0,728 & & Valid \\
\hline & $\mathrm{X} 2.6$ & Inovasi & 0,831 & & Valid \\
\hline & $\mathrm{Y1}$ & Fulfillment & 0,899 & & Valid \\
\hline & $\mathrm{Y} 2$ & Pleasure & 0,858 & & Valid \\
\hline & Y3 & Ambivalence & 0,897 & & Valid \\
\hline & Z1 & Merek & 0,885 & & Valid \\
\hline & $\mathrm{Z2}$ & Diler & 0,917 & & Valid \\
\hline & $\mathrm{Z3}$ & Kualitas & 0,898 & & Valid \\
\hline & $\mathrm{Z4}$ & Waktu & 0,826 & & Valid \\
\hline & $\mathrm{Z5}$ & Metode Pembayaran & 0,913 & & Valid \\
\hline
\end{tabular}

\section{Sumber: Data primer diolah, 2019}

Berdasarkan Tabel 4. nilai $A V E$ variabel word of mouth communication, kualitas makanan, kepuasan konsumen dan keputusan pembelian di atas 0,5. Dengan demikian dapat dinyatakan bahwa setiap variabel telah memiliki discriminant validity yang baik.

Sedangkan untuk convergen validity berdasarkan Tabel 4. diketahui bahwa masing-masing indikator variabel penelitian memiliki nilai outer loading diatas 0,5. Sehingga semua indikator dinyatakan valid atau layak untuk digunakan untuk penelitian dan analisis lebih lanjut.

Tabel 5: Hasil Uji Reliabilitas

\begin{tabular}{|c|c|c|c|c|c|}
\hline Variabel & $\begin{array}{l}\text { Composite } \\
\text { Reliability }\end{array}$ & $\begin{array}{c}\text { Nilai } \\
\text { Kritis }\end{array}$ & $\begin{array}{c}\text { Cronbach's } \\
\text { Alpha }\end{array}$ & $\begin{array}{l}\text { Nilai } \\
\text { Kritis }\end{array}$ & $\begin{array}{c}\text { Evaluasi } \\
\text { Model }\end{array}$ \\
\hline Word Of Mouth Communication & 0,785 & \multirow{4}{*}{$>0,7$} & 0,625 & \multirow{4}{*}{$>0,6$} & \multirow{4}{*}{ Reliabel } \\
\hline Kualitas Makanan & 0,904 & & 0,872 & & \\
\hline Keputusan Pembelian & 0,949 & & 0,933 & & \\
\hline Kepuasan Konsumen & 0,915 & & 0,864 & & \\
\hline
\end{tabular}

\section{Sumber: Data primer diolah, 2019}

Konstruk dinyatakan reliabel jika memiliki nilai composite reliability di atas 0,7 dan cronbach's alpha di atas 0,6. Berdasarkan Tabel 5, semua konstruk memiliki nilai composite reliability di atas 0,7 dan cronbach's alpha di atas 0,6. Jadi dapat disimpulkan bahwa konstruk memiliki reliabilitas yang baik.

\section{Pengujian Inner Model (Model Struktural)}

Pengujian inner model dilakukan untuk melihat nilai signifikasi hubungan antara variabel laten dengan uji t sesuai parameter jalur strukturalnya dan nilai R-square dari model penelitian. Pengujian tersebut dilakukan melalui SmartPLS 3.0 dengan melakukan langkah calculate-boostrapping dan diperoleh hasil sebagai berikut:

\section{Tabel 6: Path Coefficient (Mean, STDEV, T-Value, P-Values)}




\begin{tabular}{lcccccc}
\hline \multicolumn{1}{c}{$\begin{array}{c}\text { Hubungan antar } \\
\text { variabel }\end{array}$} & $\begin{array}{c}\text { Original } \\
\text { Sample }\end{array}$ & $\begin{array}{c}\text { Samples } \\
\text { Mean }\end{array}$ & $\begin{array}{c}\text { Standard } \\
\text { Deviation }\end{array}$ & $\begin{array}{c}\boldsymbol{t} \text { - } \\
\text { statistic }\end{array}$ & $\begin{array}{c}\boldsymbol{p} \\
\text { values }\end{array}$ & Keterangan \\
\hline $\begin{array}{l}\text { WOM } \rightarrow \text { Kepuasan } \\
\text { Konsumen }\end{array}$ & 0,216 & 0,219 & 0,101 & 2,121 & 0,034 & Signifikan \\
\hline $\begin{array}{l}\text { Kualitas Makanan } \rightarrow \\
\text { Kepuasan Konsumen }\end{array}$ & 0,123 & 0,130 & 0,102 & 1,205 & 0,229 & Tidak Signifikan \\
\hline $\begin{array}{l}\text { WOM } \rightarrow \text { Keputusan } \\
\text { Pembelian }\end{array}$ & 0,224 & 0,229 & 0,065 & 3,419 & 0,001 & Signifikan \\
\hline $\begin{array}{l}\text { Kualitas Makanan } \rightarrow \\
\text { Keputusan Pembelian }\end{array}$ & 0,639 & 0,638 & 0,059 & 10,810 & 0,000 & Signifikan \\
\hline $\begin{array}{l}\text { Keputusan Pembelian } \\
\rightarrow \text { Kepuasan }\end{array}$ & 0,433 & 0,427 & 0,113 & 3,812 & 0,000 & Signifikan \\
Konsumen & & & & & & \\
\hline
\end{tabular}

Sumber: Data primer diolah, 2019

Hasil pengujian pada Tabel 6. digunakan untuk menguji hipotesis yang ada. Pengujian pertama untuk melihat word of mouth communication berpengaruh positif dan signifikan terhadap kepuasan konsumen. Hasil pengujian menunjukkan bahwa nilai original sample estimate sebesar 0,216 dengan signifikansi 5\% yang di tunjukkan dengan nilai t-statistik 2,121 lebih besar dari nilai t-tabel sebesar 1,98 serta $p$-values 0,034 lebih kecil dari 0,05. Sedangkan nilai original sample estimate positif mengindentifikasikan bahwa word of mouth communication berpengaruh positif terhadap keputusan kepuasan konsumen. Berdasarkan hasil regresi tersebut dapat disimpulkan bahwa hipotesis H1 dapat diterima. Konsisten dengan hasil penelitian yang dilakukan oleh Fahima (2007) yang menyatakan bahwa word of mouth communication berpengaruh terhadap kepuasan konsumen.

Pengujian kedua dilakukan untuk melihat apakah kualitas makanan berpengaruh positif dan signifikan terhadap kepuasan konsumen. Hasil pengujian dapat dilihat dari Tabel 6, nilai original sample estimate sebesar 0,123 dengan nilai t-statistik 1,205 < 1,98 serta $p$-values 0,229>0,05 yang berarti kualitas makanan tidak berpengaruh terhadap kepuasan konsumen. Berdasarkan hasil regresi tersebut dapat disimpulkan bahwa hipotesis $\mathrm{H} 2$ tidak dapat diterima. Konsisten dengan hasil penelitian yang dilakukan oleh Kusumasasti dkk (2017) yang menyatakan bahwa kualitas produk tidak berpengaruh terhadap kepuasan konsumen DW COFFE SHOP. (Rony, 2017) dalam penelitiannya kualitas produk tidak berpengaruh signifikan terhadap kepuasan konsumen. Diperkuat dengan penelitian yang dilakukan oleh Abdullah dan Rozario (2009) kualitas layanan dan suasana memiliki hubungan yang positif dengan kepuasan pelanggan, sedangkan kualitas produk menunjukan hubungan negatif. Namun demikian hasil penelitian ini bertentangan dengan penelitian oleh Handojo dan Adinugraha (2015) yang menyatakan kualitas makanan dapat mempengaruhi kepuasan konsumen.

Pengujian ketiga dilakukan untuk melihat apakah word of mouth communication berpengaruh positif dan signifikan terhadap keputusan pembelian. Hasil pengujian dapat dilihat dari Tabel 6, nilai original sample estimate sebesar 0,224 dengan nilai t-statistik $3,419>1,98$ serta $p$-values $0,001<0,05$ yang berarti word of mouth communication berpengaruh positif dan signifikan terhadap keputusan pembelian dengan tingkat signifikansi 5\%. Berdasarkan hasil regresi tersebut dapat disimpulkan bahwa hipotesis 
H3 dapat diterima. Konsisten dengan hasil penelitian yang dilakukan oleh Nugraha dkk (2015) yang menyatakan bahwa word of mouth communication berpengaruh terhadap keputusan pembelian.

Pengujian keempat dilakukan untuk melihat apakah kualitas makanan berpengaruh positif dan signifikan terhadap keputusan pembelian. Hasil pengujian dapat dilihat dari Tabel 6, nilai original sample estimate sebesar 0,639 dengan nilai t-statistik $10,810>1,98$ serta $p$-values $0,000<0,05$ yang berarti kualitas makanan berpengaruh positif dan signifikan terhadap keputusan pembelian dengan tingkat signifikansi $5 \%$. Berdasarkan hasil regresi tersebut dapat disimpulkan bahwa hipotesis H4 dapat diterima. Konsisten dengan hasil penelitian yang dilakukan oleh Setiawan (2013) dalam penelitiannya menyatakan terdapat pengaruh antara kualitas makanan terhadap keputusan pembelian.

Pengujian kelima dilakukan untuk melihat apakah keputusan pembelian berpengaruh positif dan signifikan terhadap kepuasan konsumen. Hasil pengujian dapat dilihat dari Tabel 6, nilai original sample estimate sebesar 0,433 dengan nilai t-statistik $3,812>1,98$ serta $p$-values $0,000<0,05$ yang berarti keputusan pembelian berpengaruh positif dan signifikan terhadap kepuasan konsumen dengan tingkat signifikansi $5 \%$. Berdasarkan hasil regresi tersebut dapat disimpulkan bahwa hipotesis H5 dapat diterima. Konsisten dengan hasil penelitian yang dilakukan oleh Nugraha dkk (2015) dalam penelitiannya menyatakan terdapat pengaruh yang antara keputusan pembelian terhadap kepuasan konsumen.

Tabel 7: Specific Indirect Effects (Mean, STDEV, T-Value, P-Values)

\begin{tabular}{lcccccc}
\hline \multicolumn{1}{c}{ Hubungan antar variabel } & $\begin{array}{c}\text { Original } \\
\text { Sample }\end{array}$ & $\begin{array}{c}\text { Samples } \\
\text { Mean }\end{array}$ & $\begin{array}{c}\text { Standard } \\
\text { Deviation }\end{array}$ & t-statistic & $\begin{array}{c}\boldsymbol{p} \\
\text { values }\end{array}$ & Keterangan \\
\hline $\begin{array}{l}\text { WOM } \rightarrow \text { Keputusan } \\
\text { Pembelian } \rightarrow \text { Kepuasan } \\
\text { Konsumen }\end{array}$ & 0,097 & 0,099 & 0,042 & 2,309 & 0,021 & Signifikan \\
\hline $\begin{array}{l}\text { Kualitas Makanan } \rightarrow \\
\begin{array}{l}\text { Keputusan Pembelian } \rightarrow \\
\text { Kepuasan Konsumen }\end{array}\end{array}$ & $\mathbf{0 , 2 7 7}$ & $\mathbf{0 , 2 7 2}$ & $\mathbf{0 , 0 7 6}$ & $\mathbf{3 , 6 3 0}$ & $\mathbf{0 , 0 0 0}$ & Signifikan \\
$\begin{array}{l}\text { Sumber: Data primer diolah, 2019 } \\
\text { Sumberan }\end{array}$ & & & & & & \\
\hline
\end{tabular}

Pengujian hipotesis keenam ditunjukan untuk melihat pengaruh word of mouth communication terhadap keputusan keuangan melalui keputusan pembelian sebagai variabel mediasi (intervening). Hasil pengujian dapat dilihat pada Tabel 7. Specific Indirect Effects, nilai original sample estimate sebesar 0,097 dan nilai t-statistik sebesar 2,309 di atas nilai t-tabel 1,98 p-values $0,021<0,05$ yang berarti word of mouth communication berpengaruh positif dan signifikan terhadap kepuasan konsumen melalui keputusan pembelian. Berdasarkan hasil regresi tersebut dapat disimpulkan bahwa hipotesis H6 dapat diterima. Konsisten dengan hasil penelitian yang dilakukan oleh Rahmadevita (2011) yang menunjukkan bahwa word of mouth communication berpengaruh terhadap kepuasan konsumen melalui keputusan pembelian.

Pengujian hipotesis ketujuh ditunjukan untuk melihat pengaruh kualitas makanan terhadap kepuasan konsumen melalui keputusan pembelian sebagai variabel mediasi (intervening). Hasil pengujian dapat dilihat pada Tabel 7. Specific Indirect Effects, nilai original sample estimate sebesar 0,277 dan nilai t-statistik sebesar 3,630 di atas nilai t- 
tabel 1,98 p-values $0,000<0,05$ yang berarti kualitas makanan berpengaruh positif dan signifikan terhadap kepuasan konsumen melalui keputusan pembelian. Berdasarkan hasil regresi tersebut dapat disimpulkan bahwa hipotesis $\mathrm{H} 7$ dapat diterima. Konsisten dengan hasil penelitian yang dilakukan oleh Sugianto dan Sugiharto (2013), kualitas makanan dapat mempengaruhi kepuasan konsumen melalui keputusan pembelian.

Tabel 8: Total Effects (Mean, STDEV, T-Value, P-Values)

\begin{tabular}{|c|c|c|c|c|c|c|}
\hline & $\begin{array}{c}\text { Original } \\
\text { Sample }\end{array}$ & $\begin{array}{c}\text { Samples } \\
\text { Mean }\end{array}$ & $\begin{array}{l}\text { Standard } \\
\text { Deviation }\end{array}$ & $\begin{array}{c}t- \\
\text { statistic }\end{array}$ & p values & Keterangan \\
\hline WOM $\rightarrow$ Kepuasan Konsumen & 0,313 & 0,318 & 0,086 & 3,626 & 0,000 & Signifikan \\
\hline $\begin{array}{l}\text { Kualitas Makanan } \rightarrow \text { Kepuasan } \\
\text { Konsumen }\end{array}$ & 0,400 & 0,402 & 0,074 & 5,397 & 0,000 & Signifikan \\
\hline WOM $\rightarrow$ Keputusan Pembelian & 0,244 & 0,229 & 0,065 & 3,419 & 0,001 & Signifikan \\
\hline $\begin{array}{l}\text { Kualitas Makanan } \rightarrow \text { Keputusan } \\
\text { Pembelian }\end{array}$ & 0,639 & 0,638 & 0,059 & 10,810 & 0,000 & Signifikan \\
\hline $\begin{array}{l}\text { Keputusan Pembelian } \rightarrow \text { Kepuasan } \\
\text { Konsumen }\end{array}$ & 0,433 & 0,427 & 0,113 & 3,812 & 0,000 & $\begin{array}{l}\text { Signifikan } \\
97\end{array}$ \\
\hline
\end{tabular}

Sumber: Data primer diolah, 2019

Kemudian pada pengaruh langsung word of mouth communication terhadap kepuasan konsumen dengan koefisien jalur 0,216 sedangkan untuk pengaruh tidak langsung sebesar 0,097. Untuk melihat pengaruh totalnya pengaruh langsung ditambah dengan pengaruh tidak langsung $(0,216+0,097=0,313)$. Hasil ini memperkuat bahwa pengaruh word of mouth communication terhadap kepuasan konsumen positif (variabel eksogen dapat mempengaruhi variabel endogen secara langsung).

Pengaruh langsung kualitas makanan terhadap kepuasan konsumen dengan koefisien jalur 0,123 sedangkan untuk pengaruh tidak langsung sebesar 0,277 . Untuk melihat pengaruh totalnya pengaruh langsung ditambah dengan pengaruh tidak langsung $(0,123+0,277=0,400)$. Hasil ini memperkuat bahwa pengaruh kualitas makanan terhadap kepuasan konsumen positif (variabel eksogen dapat mempengaruhi variabel endogen secara langsung).

\section{R-square}

Pengujian terhadap inner model dilakukan dengan melihat nilai $R$-square. Hasil $R$-square terangkum dalam Tabel 9 berikut ini:

Tabel 9: R-Square

\begin{tabular}{ll}
\hline \multicolumn{1}{c}{ Endogen Variabel } & Nilai R-Square \\
\hline Keputusan Pembelian $(\mathrm{Z})$ & 0.526 \\
\hline Kepuasan Konsumen $(\mathrm{Y})$ & 0.404 \\
\hline
\end{tabular}

Sumber: Pengolahan data dengan SmartPLS, 2019

Berdasarkan sajian data pada Tabel 9. dapat diketahui nilai $R$-square untuk keputusan pembelian 0,526 yang berarti variabel word of mouth communication dan variabel kualitas makanan mempengaruhi variabel keputusan pembelian masuk dalam kategori moderat (sedang). Berdasarkan nilai $R$-square tersebut dapat dikatakan 
keputusan pembelian dipengaruhi oleh variabel word of mouth communication dan variabel kualitas makanan sebesar 52,6\%, sedangkan sisanya 47,4\% dipengaruhi oleh variabel lain yang tidak diteliti.

Nilai $R$-square kepuasan konsumen sebesar 0,404 yang artinya variabel word of mouth communication, kualitas makanan dan keputusan pembelian mempengaruhi variabel kepuasan konsumen masuk dalam kategori moderat (sedang). Berdasarkan nilai $R$-square tersebut dapat dikatakan kepuasan konsumen dipengaruhi oleh variabel independen dan variabel mediasi (intervening) sebesar 40,4\%, sedangkan sisanya 59,6\% dipengaruhi oleh variabel lain yang tidak diteliti.

Selanjutnya untuk menghitung nilai Q Square dapat dilakukan sebagai berikut.

Diketahui: $\quad R_{1}^{2}=0,526$

$$
Q^{2}=1-\left(1-R_{1}^{2}\right)\left(1-R_{2}^{2}\right) \ldots\left(1-R_{p}^{2}\right)
$$

Maka:

$$
R_{2}^{2}=0,404
$$

$Q^{2}=1-\left(1-R_{1}^{2}\right)\left(1-R_{2}^{2}\right)$

$Q^{2}=1-(1-0,526)(1-0,404)$

$Q^{2}=1-(0,474)(0,596)$

$Q^{2}=1-(0,283)$

$Q^{2}=0,717$

Apabila $Q$-squre lebih dari 0 (nol), maka model layak dikatakan memiliki nilai prediktif yang relevan. Besarnya $Q^{2}$ memiliki nilai dengan rentang $0<Q^{2}<1$, dimana semakin mendekati 1 berarti model semakin baik. Berdasarkan perhitungan di atas nilai Prediction Relevance (Q Square) adalah 0,717 yang artinya memiliki kapasitas prediksi yang besar dan model yang baik.

\section{SIMPULAN}

Penelitian ini memberikan bukti empiris mengenai word of mouth communication dan kualitas makanan terhadap kepuasan konsumen melalui keputusan pembelian. Penelitian ini dilakukan di Restaurant J'S Kitchen and Lounge Kalawa Waterpark, Palangka Raya. Hasil penelitian menunjukkan bahwa:

Word of mouth communication berpengaruh positif dan signifikan terhadap kepuasan konsumen di Restaurant J'S Kitchen and Lounge. Kualitas makanan tidak berpengaruh terhadap kepuasan konsumen di Restaurant J'S Kitchen and Lounge. Word of mouth communication berpengaruh positif dan signifikan terhadap keputusan pembelian di Restaurant J'S Kitchen and Lounge. Kualitas makanan berpengaruh positif dan signifikan terhadap keputusan pembelian di Restaurant J'S Kitchen and Lounge. Keputusan pembelian berpengaruh positif dan signifikan terhadap kepuasan konsumen di Restaurant J'S Kitchen and Lounge. Word of mouth communication berpengaruh positif dan signifikan terhadap kepuasan konsumen melalui keputusan pembelian di Restaurant J'S Kitchen and Lounge. Kualitas makanan berpengaruh positif dan signifikan terhadap kepuasan konsumen melalui keputusan pembelian di Restaurant J'S Kitchen and Lounge.

Saran yang dapat diberikan dengan berdasarkan hasil penelitian adalah: Penelitian selanjutnya diharapkan dapat melakukan pengujian model yang lebih 
dikembangkan, sehingga hasil penelitian dapat lebih memberi gambaran yang lebih baik. Penelitian selanjutnya diharapkan dapat menambah variabel-variabel lain yang mempengaruhi kepuasan konsumen di restoran, menggunakan populasi dan sampel yang lebih banyak dan mempertimbangkan penggunaan objek dalam melakukan penelitian.

\section{REFERENSI}

Abdullah, D. N. M. A., \& Rozario, Francine. (2009). Influence of service and product quality towards customer satisfaction: A case study at the staff cafeteria in the hotel industry. World Academy of Science, Engineering and Technology, hlm 185-190.

Essinger, James \& Wylie, Helen. (2003). Customer loyalty: Devising successful strategies in food and drink.

Fahima, Lim. (2007). Word of Mouth Kalahkan Pengaruh Iklan ATL. Diakses pada tanggal 30 November 2013 dari www.virtual.co.id

Ghozali, Iman \& Latan, Hengky. (2015). Partial Least Squares Konsep, Teknik dan Aplikasi menggunakan Program SamartPLS 3.0. Semarang: Undip

Handojo, S, M., \& Adinugraha, A. T. (2015). Analisis Pengaruh Kualitas Makanan Dan Persepsi Harga Terhadap Kepuasan Konsumen Di D'cost Surabaya. Jurnal Hospitality dan Manajemen Jasa, hlm 643-654.

Irwan, D. H. (2008). Smarter Marketing Moves: Membangun Keunggulan Melalui Informasi, Komunikasi dan Produk. Jakarta: Media Elex Komputindo Kelompok Gramedia-Jakarta IKAPI.

Kusumasasti, Ika., Andarwati., \& Hadiwidjojo, Djumilah. (2017). Pengaruh Kualitas Produk Dan Layanan Terhadap Loyalitas Pelanggan Coffee Shop. EKOBIS Ekonomi Bisnis Vol. 22, No. 2, Oktober, hlm 123 - 129.

Kotler, Philip \& Keller, Kevin Lane. (2008). Manajemen Pemasaran. Jakarta: Indeks. . (2012). Manajemen Pemasaran Edisi 13. Jilid 1. Jakarta: Erlangga.

Nugraha, Diyos \& Saraswati, Trisha Gilang. (2015). Pengaruh Word Of Mouth Terhadap Keputusan Pembelian Pada Cafe Roti Gempol Dan Kopi Anjis. eProceedings of Management.

Rahmadevita, D. L. (2011). Pengaruh Reputasi Merek dan Komunitas Pelanggan terhadap Nilai Pelanggan, Word Of Mouth serta Keputusan Pembelian. Jurnal Profit. Volume 7 No. 1.

Rony. (2017). Pengaruh Kualitas Produk dan Suasana Café (Store Atmosphere) Terhadap Keputusan Pembelian Konsumen dan Dampaknya Terhadap Kepuasan Konsumen (Studi Kasus Pada Alila Café Pontianak). Jurnal Manajemen Update. Vol 6, No2 (2017).

Sari, D. W. C. (2017). Pengaruh Kualitas Makanan, Pelayanan, Harga Dan Suasana Restoran Terhadap Keputusan Pembelian. Jurnal Ekonomi Dan Kewirausahaan 17.

Sernovitz. (2012). Word of Mouth Marketing: How Smart Companies Get People Talking. Chicago: Pressbox.

Setiawan, M. F. (2013). Analisa pengaruh food quality dan brand image terhadap keputusan pembelian roti kecik toko roti Ganep's di Kota Solo. Jurnal Strategi Pemasaran 1.1.

Sugianto, Jimmy \& Sugiharto, Sugiono. (2013). Analisa pengaruh service quality, food 
quality, dan price terhadap kepuasan pelanggan restoran Yung Ho Surabaya Jodurnal Manajemen Pemasaran, hlm 1-10.

Sugiyono. (2014). Metode Penelitian Bisnis. Bandung: Alfabeta.

Sugiyono. (2016). Metode Penelitian Pendidikan Pendekatan Kuantitatif, kualitatif, dan $R \& D$. Bandung: Alfabeta.

Zeithaml., Bitner \& Gremler. (2006). "Services Marketing: Integrating Customer Focus Across The Firm", Singapore, The MCGraw-Hill Companies. 